concept arises from 4 phases of growth: phase of intrauterine growth, phase of completed postnatal adjustment in first 3 weeks of life forming a percentile below birth percentile, phase of stable growth targeting birth weight percentile at 42 $+0 / 7$ week, according to Fenton chart and phase of preterm infant growth after term age monitored with WHO growth charts. The aim of this study is to present a new approach for personalized postnatal growth trajectories for preterm infants and to compare them with growth percentiles of our patients. This concept still needs to be validate in a larger sample size. Data from 39 preterm infants gestational age (GA) 29-33+6/7 weeks and birth weight $(\mathrm{BW})<2000 \mathrm{~g}$ were collected. Retrospective, for every infant, a new personalized growth chart was drawn using online calculator (https://www. growthcalculator.org/) and was compared with existing growth trajectory measured from birth to discharge. The difference between measured (MW) and predicted weights (PW) of our patients were calculated and analyzed, together with their characteristics, comorbidities, treatment and nutrition. Preliminary results show that the most of them $(\mathrm{N}=22)$ deviated less than $5 \%$ of ideal weight (PW) and there were no differences between sexes. Statistically significant deviation in median for MW and PW was noticed in a preterm infants GA $>32$ weeks. Remaining results will be presented after analysing data of total number of patients collected from hospital records from period 2018 to 2020. Adjusting nutrition in the earliest phase of postnatal life towards an ideal personalized growth trajectory, can have an optimal impact in growth, body composition and neurodevelopment of the infant and can reduce the risk of some early onset adult metabolic and cardiovascular diseases. Therefore, it is necessary to create more precise tools in monitoring growth of preterm infants, such as personalized growth trajectories.

\section{KAPOSIFORM HAEMANGIOENDOTHELIOMA WITH KASABACH-MERRITT PHENOMEN IN A NEWBORN: A CASE REPORT}

Karmen Kondža*, Ivančica Škarić. Children's Hospital Zagreb, Zagreb, Croatia

10.1136/archdischild-2021-europaediatrics. 141

Kaposiform haemangioendothelioma ( KHE) is a rare vascular tumor and has high mortality rate in newborns when associated with Kasabach-Merritt syndrome ( KMS) due to consumptive coagulopathy.

Methods Female newborn, GA 30 w, BM 2220g, due to the threatening asphyxia, born by S.C., with respiratory distress syndrome (RDS) and extremly massive soft tissue purple tumor with swollen erythematous, inhomogenous skin. The tumor was spread over lower abdominal wall, vulva, gluteal region, whole right tight and upper part of the left tight. The baby was anemic ( $\mathrm{Hb} 97 \mathrm{~g} / \mathrm{l})$, trombocytopenic ( 8x109/L) with consumptive coagulopathy (immeasurable fibrinogen). RDS was treated with exogenous surfactant and mechanical ventilation. As soon as possible she received packed red blood cell transfusion, platelet transfusion, fibronogen concentrate, INN-eptacog alfa (activated). On the ultrasound of the abdomen paralytic ileus and hemorrhagic effusions were found. Doppller ultrasound of the tumor expressed heterogenous echogenicity and hypervascular pattern. Hour by hour the tumor grew larger. In spite of all intensive treatment baby developed multiorgan failure (MOF) and died in the of 18 hours.

Results Patohistologically, the tumor consists of irregular, predominantly small and slit-like vascular spaces lined with spindle endothelial cells which sometimes form nodular structure. On immunohistochemistry the spindle cells had positive reaction for CD31, CD34, D2-40 and negative reaction for GLUT-1. The finding corresponds to KHE.

Conclusions We report a premature born neonate with a huge KHE associated with fulminant form of KMS and developed consumptive coagulopathy resulting in multiorgan failure and death within 18 hours.

\section{Paediatric Allergology and Clinical Immunology}

\section{DRUG-INDUCED ENTEROCOLITIS SYNDROME (DIES) IN 6-YEAR OLD GIRL}

Renata Vrsalović*, Iva Škorić, Iva Mihatov Štefanović, Biserka Čičak. Department of Pediatrics, Sestre milosrdnice University Hospital Center, Zagreb, Croatia

\subsection{6/archdischild-2021-europaediatrics. 142}

Drug-induced enterocolitis syndrome (DIES) is an uncommon, non-IgE-mediated drug hypersensitivity reaction that can be severe and potentially life-threatening disease. Because of the clinical resemblance with enterocolitis syndrome induced by food proteins (FPIES), DIES is also called 'FPIES-like' reaction and similar diagnostic criteria are proposed. We report the case of a 6-year old girl who was admitted to our Department for an oral challenge test with amoxicillin (AMX).

She was under the supervision of pulmonologist for recurrent wheezing episodes. During the outpatient- follow up mother reported multiple reactions after the ingestion of amoxicillin +/- clavulanic acid. After the first administration of oral suspension girl developed an erythematous skin rash, abdominal pain followed with an acute episode of repetitive vomiting.

Next two administrations were followed with a short period of drowsiness, abdominal pain, repetitive vomiting and severe diarrhea 1-2 hours after drug ingestion. The symptoms spontaneously resolved within 24 hours. During the last reaction parents called an ambulance because of drowsiness and poor general condition after severe vomiting and diarrhea, and girl was treated shortly with intravenous infusion.

In the allergy study performed, specific IgE to amoxicillin was negative as well as basophil activation test for Augmentin ${ }^{\circledR}$.

Consecutively, we performed an open 3-step graded oral provocation test with AMX in a hospital setting according to the published guidelines.

Approximately 3 hours after receiving the first dose $(5 \mathrm{mg})$ and 1 hour after the second dose $(50 \mathrm{mg})$, she developed severe abdominal pain, nausea and repetitive vomiting, and two hours later she became pale and developed severe diarrhea. During the reaction, she had no cutaneous or respiratory symptoms, and she remained hemodynamically stable. A blood test obtained 1 hour after the onset of the reaction showed normal complete blood cell count. She was parenterally hydrated. Approximately 5-6 hours after onset of symptoms she showed progressive improvement to a complete recovery. 
Considering previous reactions, laboratory findings and results of the oral challenge test, we suggest that our patient meets the criteria for DIES by amoxicillin. We performed a comprehensive literature search and found three cases of DIES reported in children and one in an adult patient who developed a severe reaction with shock.

In our opinion, the clinical awareness on DIES and its potential severity should be improved and it is important to distinguish it from side effect of the drug.

\section{DRUG ALLERGY - 5- YEAR CASE SERIES}

Ana Rita Curval*, Beatriz Vieira, Juliana da Silva Cardoso, Maria José Dinis. Pediatrics Department, UAG da Mulher e da Criança, Centro Hospitalar Universitário de São João, Porto

\subsection{6/archdischild-2021-europaediatrics.143}

Drug allergy suspicion is a frequent reason for referral to allergology specialty in pediatric age. However, this suspicion is rarely confirmed, and the drug provocation test (DPT) is fundamental for the diagnosis. Thus, with this work we intend to characterize the pediatric population with suspected drug allergy referred to the Pediatric Allergology consultation.

Retrospective analysis of the clinical processes of children ( $<18$ years) with suspected drug allergy followed in the Pediatric Allergology consultation between 2015 and 2019. Demographic data, history of allergic disease, clinical manifestations, performed therapy and guidance were evaluated.

The sample included 118 children, 54\% female, with an average age of 5 years and 2 months (range from 5 months to 18 years). 38 children had a personal history of atopy, including recurrent wheezing and atopic dermatitis, and 29 children had an history of allergy in first-degree relatives. The reactions that increased the suspicion of drug allergy were mostly mucocutaneous $(\mathrm{n}=$

107) and gastrointestinal $(n=11) .49$ children were observed in the emergency service for this reason. They were medicated with isolated antihistamine $(n=33)$, antihistamine + corticosteroid $(\mathrm{n}=11)$ and antihistamine + corticosteroid + adrenaline $(n=5)$. IgEs were specifically quantified in 106 cases (for Amoxicillin, Ampicilloil and Penicilloic G and V), with a positive result in only 2. DPT were performed for antibiotics (amoxicillin $(\mathrm{n}=53)$, amoxicillin/clavulanic acid $(\mathrm{n}=$ 49), penicillin $(n=4)$, cefuroxime $(n=2)$, azithromycin $(n=$ $1)$, cefixime $(n=1))$, paracetamol $(n=5)$ and ibuprofen $(n=1)$, with a positive result in 4 children. Verified reactions were mucocutaneous and gastrointestinal, without cases of anaphylaxis.

Drug allergy in children is an important topic of debate, as overdiagnosis is quite common, hindering the clinical approach and leading to the eviction of several first-line therapies. Thus, we want to alert to the importance of an early referral in order to obtain a correct and clear diagnosis.

\section{ANALYSIS OF THE PREVALENCE OF ALLERGIC DISEASES IN ADOLESCENTS IN THE RUSSIAN FEDERATION}

Elena Kaitukova*, EA Vishneva, EV Komarova, LS Namazova-Baranova, AA Alekseeva. Central Clinical Hospital of the Russian Academy of Sciences, Moscow

10.1136/archdischild-2021-europaediatrics. 144
To assess prevalence of allergic diseases among schoolchildren in the Russian Federation (RF) in the age groups of 11 and 15 years.

The data obtained during the screening of schoolchildren (which included surveys of parents and school doctors with specially designed questionnaires, an allergist's examination, spirometry) -the project of the RF and the WHO European Office for the development of the school medicine network. 2114 schoolchildren were examined in the following federal districts: Central Federal District - CFD, Southern Federal District - SFD, North-Western Federal District - NWFD, Volga Federal District - VFD, Ural Federal District - UFD, Siberian Federal District - SibFD, Far Eastern Federal District - FEFD.

Analysis of the results suggests that the smallest number of children with manifestations of allergic diseases was noted in the SibFD $\mathrm{n}=81(24 \%)$, and the largest in the UFD $\mathrm{n}=$ 107 (36\%); by districts: in the CFD $\mathrm{n}=83$ (31\%), NWFD $\mathrm{n}$ $=87(32 \%)$, FEFD $\mathrm{n}=91(30 \%)$, SFD $\mathrm{n}=100(30 \%)$, VFD $\mathrm{n}=102(32 \%)$.

At the same time, the average of bronchial asthma (BA) was $2 \%$, seasonal allergic rhinitis (SAR) $-8 \%$, allergic rhinitis (AR) $-8 \%$, atopic dermatitis

- 2\%, food allergy (FA) - 13\%, drug allergy (DA) - 3\%. Regional peculiarities were revealed: the prevalence of BA varied from $1-1.5 \%$ in the NWFD, VFD, FEFD, SFD to $6 \%$ in the UFD. The prevalence of seasonal AR ranged from $2 \%$ in the NWFD and $3 \%$ in the FEFD to $12 \%$ in the UFD and $16 \%$ in the North Caucasus Federal District. Perennial AR accounted for from $3 \%$ in the CFD to $11 \%$ in the UFO and $16 \%$ of the FEFD. The highest incidence of food allergy was registered in the Volga Federal District and CFD, 17\% and $16 \%$, respectively, and only $10 \%$ in the SFD and in the SibFD. AD was diagnosed in equal shares in the CFD and NWFD (3\%), in the UFD - $2 \%$, in the SFD, VFD, SFD and FEFD - $1 \%$.

The true prevalence of allergic diseases among schoolchildren of the Russian Federation is significantly higher than data of official statistics but differs by regional peculiarities. The true prevalence has appeared to be in

2-20 times above the data of official statistics: data of official statistics for BA in 2015 amounted to 2,7\%, for AR $0,9 \%$.

\section{NOVEL MARKERS FOR ATOPIC DERMATITIS PHENOTYPES AT CHILDREN}

Volodymyr Dytiatkovskyi, Olexandr Abaturov. S/ 'Dnipropetrovsk Medical Academy of the MH of Ukraine'

10.1136/archdischild-2021-europaediatrics. 145

To study the associations of onset and progression risks of atopic dermatitis (AD) phenotypes as a mono-nosology or combined with seasonal allergic rhino-conjunctivitis (SARC) and/or perennial allergic rhinitis

(PAR) at children with serum concentrations of immunoglobulin (IgE) total, cutaneous T-cell attracting chemokine (CTACK) and thymus and activation regulated chemokine (TARC).

We recruited 39 patients into the main group suffering from different $\mathrm{AD}$ phenotypes (as mono-nosology and combined with SARC and/or PAR) and 47 patients - into the 